\title{
Glycemic response of honey and dates consumption
}

\author{
Dalia A. Ali $\odot$, Reder R. Mohammedsalih (1) and Rafiq M.S. Rashid ( 1 \\ Department of Food Science and Quality Control, College of Agricultural Engineering Sciences, University of Sulaimani, Sulaymaniyah, \\ 46001, Iraq
}

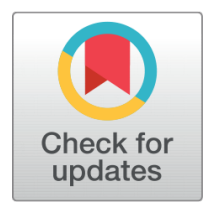

Received 27-10-2021
Revised 08-12-2021
Accepted 21-12-2021
Published 31-01-2022

Corresponding Author Dalia A. Ali

dalia.ali@univsul.edu.iq

Department of Food Science and Quality Control, College of Agricultural Engineering Sciences, University of Sulaimani, Sulaymaniyah, 46001, Iraq

DOI https://doi.org/10.47419/ bjbabs.v3i01.83

\section{Pages: 17-28}

Distributed under the terms of the Creative Commons

Attribution-NonCommercial 4.0 International (CC-BY-NC 4.0), which permits use for any non-commercial purpose, distribution, and reproduction in any medium, provided that the original work is properly cited.

Copyright: (C) 2022 Dalia A. Ali, Reder R. Mohammedsalih, Rafiq M.S. Rashid

\section{OPEN ACCESS}

\section{ABSTRACT}

Background and objective: The current study aims to evaluate the glycemic index of local honey and date intake in healthy adults.

Methods: The study was conducted on 24 healthy volunteers. They were given $50 \mathrm{~g}$ of carbohydrates from Haji Omeran local honey, Khudri (or Khadrawi) local date and reference food (white bread). The average body mass index and age of volunteers are almost similar. The blood samples were collected from finger capillaries to assess the glucose levels by using glucometer at selected time points ( 0 , $15,30,60,90$, and 120 minutes). The data was recorded and statistically analyzed by one-way ANOVA and Duncan comparison.

Results: The study results showed that the glycemic index of the honey and date is classified as a medium glycemic index, referring to their high carbohydrates content. The results also indicated that honey and dates have significantly different effects $(P<0.05)$ on the blood glucose responses compared to reference food (white bread) in healthy subjects. The mean blood glucose levels after honey ingestion were higher than that when the date was ingested and lower than that of the reference food. In addition, the blood glucose responses for different foods in the study for females and males are not significantly different $(P>0.05)$.

Conclusions: In conclusion, eating behavior regarding honey and date consumption, particularly portion size and ingestion timing, is essential to manage blood glucose levels. Thus, glycemic index values should be considered in promoting a healthy lifestyle from chronic related metabolic disorders especially, diabetes mellitus, cardiovascular disease, and obesity.

Keywords blood glucose response, date, diabetes, glucose, glycemic index, honey, reference food

\section{INTRODUCTION}

Honey and date are rich in simple carbohydrates, mainly glucose and fructose. They are also consumed widely in middle eastern countries. In addition, they are defined as staple food products at breakfast, and that is frequently administered in the form of snakes and for breaking the fast in the holy month of Ramadan. ${ }^{1,2}$ 
Honey is a natural sugary product produced by honey bees (Apis mellifera). ${ }^{3}$ Natural honey is a sticky and viscous solution with an estimated percentage content of 80-85 carbohydrates that is mainly fructose (36-50) and glucose (28-36), and the remaining are 15-17 water, 0.1-0.4 protein, and 0.2 ash. ${ }^{4}$ Besides, date palm (Phoenix dactylifera L.) is one of the oldest fruit source known in the dry and semidry areas. ${ }^{5}$ The date fruit has more than $80 \%$ sugars, and the remaining $20 \%$ is fiber, lipid, protein, and ash. ${ }^{6}$ Although the chemical composition of a date varies according to the stage of ripening, growing condition, and others, generally; dates rich in sugar ( $71.2-81.4 \%$ of dry weight). The main sugars are fructose and glucose. ${ }^{7}$

Dietary carbohydrates became a target for scientific research due to their effect in elevating blood glucose level (BGL) and insulin secretion, in particular foods that contain a high amount of sugar, such as honey and dates with an average glycemic index (GI) values of $61 \pm 3$ and $42 \pm 4$, respectively. ${ }^{8-10}$ With the presence of such an effect, the GI has become a current topic for assessing the impact of different carbohydrates-containing foods on BGL and their impact on health. ${ }^{11}$ So it is important to investigate the food GI and examine its influence on both healthy and sick individuals. The findings will accordingly be useful in introducing many dietary therapies and strategies in many chronic illnesses. ${ }^{12}$

The GI was first proposed in 1981 to categorize food items by the glycemic response. The food GI depends on the quickness of digestion and absorption of its carbohydrates, which is determined mainly by its chemical and physical properties. A particular food item's GI is determined by measuring the blood glucose (BG) response following food consumption (containing carbohydrate) relative to a carbohydrate-containing reference food, typically glucose or white bread named standard food. ${ }^{12,13}$ GI ranks carbohydrate-containing foods based on how quickly they elevate blood sugar concentration. By comparing the area under the BG response curve of the test food with that of the reference food, which provides a relative value of 100 . In this context, foods are given a numeric value, and then generally classified as having a low ( $\leq 55)$, moderate (56-69), or high $(\geq 70)$ GI. ${ }^{14}$ In 1995, after the first publication of 62 foods' GIs, an expansion list of about 550-600 common western foods was included in the international table of GI. ${ }^{15}$ Since the concept of diet GI introduced, there has been considerable research interest in GI contribution to the states of health, both in terms of management and prevention of certain metabolic disorders. In 2002, 2008, and 2021 the original table updated to more than 3450 items of food and reached 4000 items in total due to GI's important insight. ${ }^{8}$ Diseases in which GI has been shown to play a critical role include type 2 diabetes (T2D) and prediabetes states of impaired glucose test (IGT), cardiovascular disease (CVD), obesity, and certain cancers. ${ }^{8,16-18}$

The spike and abnormally high BG dysregulate the insulin-producing beta cells in the pancreas and prolong blood saturation with glucose, eventually leading to increased betacell failure and further elevated BG to be a characteristic disease like diabetes if not controlled. Therefore, it is substantial to target the prevention of any extreme rises in BG concentration to reduce the risk of beta-cell failure and prevent the development of diabetes mellitus (DM). ${ }^{19}$ Considering high fructose diet consumption may also increase insulin resistance and lipogenesis in the liver due to metabolic affinity to be stored as glycogen and 
indirectly lead to fat metabolic disorders. ${ }^{20,21}$ Thus, a healthy food choice guide advocates the integration of low GI foods with a complex non-starchy polysaccharide diet, as may represent a potential strategy to decrease the risk of developing DM. ${ }^{17,22}$ This study aimed at investigating the local honey and dates GI according to the glycemic response in the healthy volunteers (human trial). Also, to find out the effect of gender on glycemic response. In addition, to take a side and restate the nutritional awareness on the impact of local honey and date on BGL.

\section{MATERIALS AND METHODS Participants}

The research was conducted at the Food Sciences and Quality Control Department, College of Agricultural Engineering Sciences, University of Sulaimani. The study relies on the Food and Agriculture Organization (FAO) and the World Health Organization (WHO) 1998 GI testing protocol. ${ }^{23,24}$ The study was approved by the Ethical Committee of the College of Agricultural Engineering Sciences, University of Sulaimani as well as it followed the principles of the Declaration of Helsinki. All volunteers were updated about the study aims, and confirmation was collected accordingly.

\section{Glycemic index testing}

A twenty-four healthy human volunteer (females 12 , males 12 ), free from any chronic illnesses and not using any medicines, enrolled for this study. The average body mass index (BMI) and age of volunteers were $20.6 \pm 2.7 \mathrm{~kg} / \mathrm{m} 2$ and $22.4 \pm 1.5$ years, respectively. The GI testing started at 8:30 am. Portions of tested foods (Haji Omran local raw unfiltered honey, local Khudri or Khodri or Khadrawi date at tamer stage), and standard food (white bread) comprising of $50 \mathrm{~g}$ available carbohydrates were given to the subjects in random order and on separate occasions (days) after an overnight fast of $\geq 10$ hours. A standard drink of pure water $(150 \mathrm{ml})$ was also provided with each test food. ${ }^{23,25}$

Each volunteer had to have from 6-8 experimental sets and was requested to ingest each test food within 3-4 minutes. The average values are used to calculate the GI of the test foods. ${ }^{26}$ BGL was determined using a professionally calibrated glucometer (Accu-Chek Aviva plus, Roche, USA) following standard procedures. Each participant's blood sample was collected through a capillary finger prick using a lancet at fasting, 0, 15, 30, 45, 60, 90, and 120 minutes. The logical time setting was based on the FAO method to determine GI of food and American Diabetic Association (ADA) criteria. After eating food, insulin will start to function immediately, and within 2 hours, postprandial BGL returns to the premeal level in healthy people. ${ }^{23,27}$ Each blood sample was placed on a test strip which was inserted into a calibrated glucometer, and the BGL was measured. ${ }^{22,23,27}$ 
The area under the glycemic response curve for each food is provided in a percent of the mean response to the standard reference food taken by the same subject and ignoring the area below the fasting concentration. The incremental area under the curve (IAUC) and GI calculation were performed according to the methods described by another research. ${ }^{23}$ The GI values calculated as:

$$
G I=\left(\frac{I A U C \text { test food }}{I A U C \text { standard reference food }}\right) \times 100
$$

\section{Statistical analysis}

The IAUC and GI data were subjected to statistical analysis using GraphPad Prism v9.1.1. The data also analyzed by one-way analysis of variance (ANOVA), and the means were compared by the (Duncan) test as described by Statistics Analysis Program (XLSTAT, 2016) with significant differences were defined at $P<0.05$. Results were expressed for baseline characteristics of the study subjects as mean \pm standard error of the mean (SEM) for BG responses.

\section{RESULTS AND DISCUSSION}

The study was performed to evaluate and compare the glycemic response of honey, date, and references food in healthy volunteers. In different time intervals $(0,15,30,60,90$, and 120 minutes), the BGL data after ingesting tested foods from the 24 healthy individuals demonstrate in Table 1 and Figure 1.

According to ADA criteria, all the participants were at healthy state; the mean of fasting BG was within the normal range around $93.7 \mathrm{mg} / \mathrm{dL}$, and there were no differences in the impaired fasting BG value. In addition, the oral glucose tolerance test (OGTT) was at normal range values and did not increase to higher levels of more than 150 or $200 \mathrm{mg} / \mathrm{dL}{ }^{28}$

The results generally show an initial increase in BGL after 15 minutes of ingesting the tested foods. Then the level reached the peak at 30 minutes for the date, the BGL was at $125.62 \mathrm{mg} / \mathrm{dL}$, and $123.91 \mathrm{mg} / \mathrm{dL}$ for honey. Followed by a gradual decline to $93.04 \mathrm{mg} / \mathrm{dL}$ and $93.16 \mathrm{mg} / \mathrm{dL}$ for date and honey, respectively, at postprandial 120 minutes because the participants were healthy, and the BGL returned to the pre-meal level.

On the other hand, the IAUC generally for reference food $(3005.07 \mathrm{mg} / \mathrm{dl} / \mathrm{min})$ was higher than the tested foods (honey $1809.33 \mathrm{mg} / \mathrm{dl} / \mathrm{min} \&$ date $1878.79 \mathrm{mg} / \mathrm{dl} / \mathrm{min}$ ) as shown in Table 1.

The differences in IAUC refer to the variation in the GI of honey 60.21 and the date GI 62.52. Therefore, based on the IAUC calculation, the GI for both tested food samples was at the medium class of the GI classification range. ${ }^{14}$

The results indicated that honey and date have significantly different $(P<0.05)$ effects on the BG responses compared to the reference food, as shown in Table 1 with further detail. 


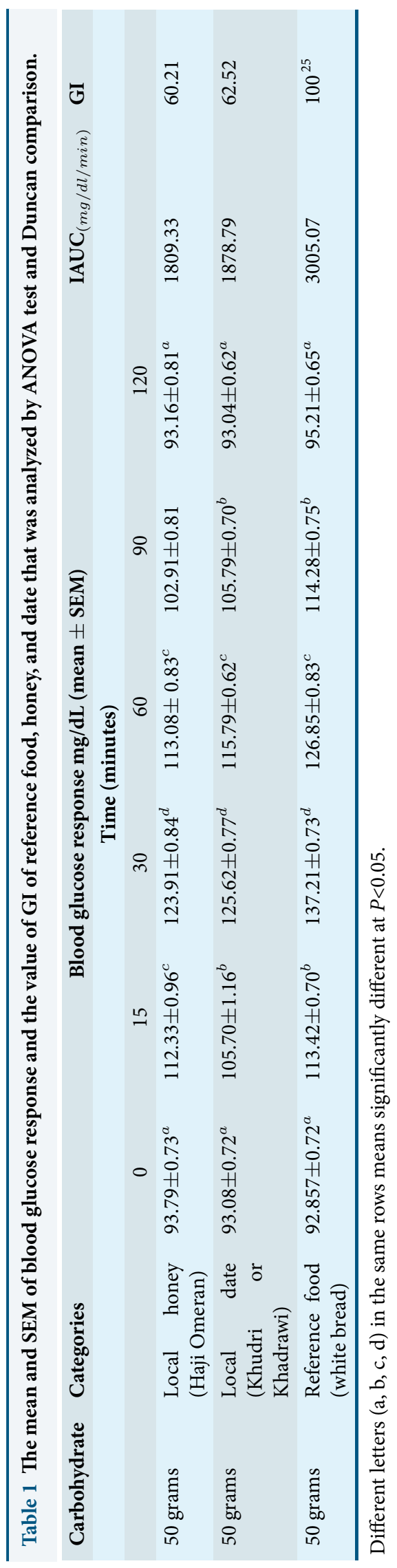






Figure 1 Mean of blood glucose responses of volunteers after ingesting the tested foods (honey, date, and reference food).

Furthermore, the obtained GI value of honey (60.21) is almost similar to Australian honey GI that was $59 \pm 5 .{ }^{29}$ Likewise, as stated in another research that Khudri date contains $74.56 \%$ carbohydrates with $61.7 \mathrm{GI},{ }^{30,31}$ that is comparable with the obtained result (62.52 GI) in this study. Despite these confirmations, different kinds of honey have a wide scale of GI due to bees making it from various sources of flora that affect sugar content and types of honey. ${ }^{32}$ Also, date has a different variety and stage of maturity, contributing to alteration in GI value. ${ }^{33}$

The carbohydrate content is the primary influence factor to consider when testing for GI value. It is essential to realize that most of the carbohydrates in Khudri date and local honey are monosaccharides. The estimated amount of fructose is around $37.12 \%$ and glucose $33.33 \%$ in date, ${ }^{30,31}$ and the honey contains approximately $63.83 \%$ of reducing sugar mainly (fructose and glucose) and sucrose (4.09\%). ${ }^{34}$ Therefore, high consumption of available and ready-GI-monosaccharide sugar might be a critical factor in carbohydrate food choice because it passes through the digestion and absorption processes rapidly and cause the rise of BGL. High blood glucose that activates insulin secretion may stimulate lipogeneses metabolism in the liver in the long term. Such a metabolic orientation has required attention due to the high fructose content that may results in insulin resistance and metabolic disorders such as diabetes. ${ }^{17,32,35}$

According to ADA, the increase in blood sugar level may not be harmful at the present test time. ${ }^{36}$ However, depending on GI values, date and honey with medium GI value may have a negative health consequences in the future, especially for people with a family his- 
tory with diabetes and other health problems. By inducing hyperglycemia and hyperinsulinemia, many studies revealed that a high GI diet may increase the risk of chronic diseases, including obesity, T2D, and CVD. ${ }^{37}$ On the contrary, a low GI diet exhibit a reduced rate of absorption of carbohydrate, giving better control over serum glucose and decreasing insulin demand that helps prevent and manage various associated disorders. ${ }^{38}$ Adopting strategical dietary plan is undoubtedly support in GI control; for instance, dietary fiber content and with less sensitive affect the amount of protein content in food may affect the value of GI via the various mechanism of action (gastric emptying, starch enzymatic digestion reduction, and decreasing the mucosa absorption rate). ${ }^{17,39}$ However, date and honey are low in fiber and protein, especially honey. ${ }^{4,7}$

Furthermore, the gender effect and association to BG response for the tested foods in the study shows that females and males responses were not significantly $(\mathrm{P}>0.05)$ different if compared time by time as shown in Figure 2. The outcome is also supported by the result data mentioned in the other research. ${ }^{40}$

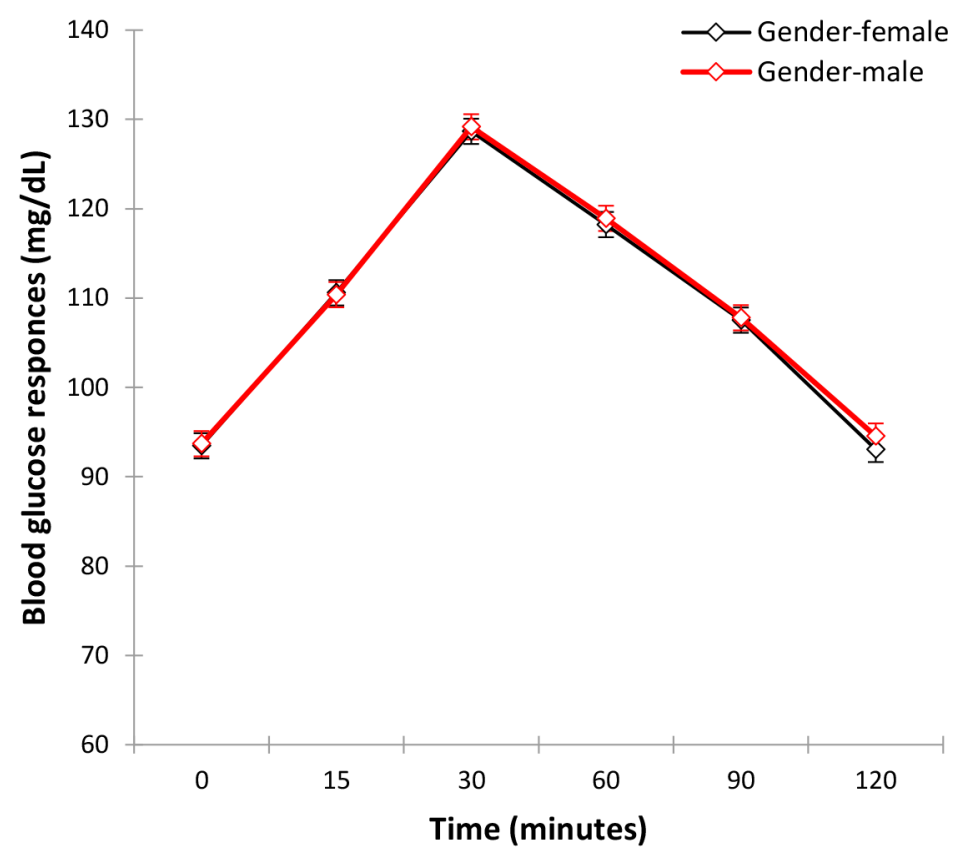

Figure 2 Comparison of mean blood glucose responses for different test foods that females and males ingested by Duncan comparison test at the level of $P<0.05$.

\section{CONCLUSIONS}

Depending on the research result, honey and date increase BG due to the high carbohydrate content that mainly consists of glucose and fructose with medium GI. Therefore, paying attention to eating behavior and food choice, including frequent ingestion, dietary 
intake combination, portion size, timing, especially on an empty stomach, are critical nutritional management. Ultimately, preventing the rapid increase of BGL in the long-term might be recommended to mitigate the risk factor of developing health problems such as diabetes, CVD, and obesity.

\section{ABBREVIATIONS}

ADA, American Diabetic Association; ANOVA, analysis of variance; BG, blood glucose; BGL, blood glucose level; BMI, body mass index; CVD, cardiovascular disease; FAO, Food and Agriculture Organization; GI, glycemic index; IAUC, incremental area under the curve; IGT, impaired glucose test; OGTT, oral glucose tolerance test; SD, standard deviation; SEM, standard error of the mean; T2D, type 2 diabetes; WHO, World Health Organization.

\section{ACKNOWLEDGEMENTS}

The authors would like to thank Prof. Mohammad Saeed Zainulabideen (Department of Food Science and Quality Control, College of Agricultural Engineering Sciences, University of Sulaimani) for his suggestion about glycemic index calculation.

\section{DECLARATIONS}

\section{Authors' contributions}

All authors have equally contributed to this work, reviewed and approved the final version of the manuscript before publishing.

\section{Conflict of interest}

The authors declare no conflict of interest.

\section{Ethical approvals}

The current study and its protocol were approved by the Ethical Committee of the College of Agricultural Engineering Sciences, University of Sulaimani, as well as it followed the principles of the Declaration of Helsinki. All volunteers were updated about the study aims, and confirmation was collected accordingly.

\section{Data availability}

The data that support the findings of this study is available from the corresponding author, upon reasonable request.

\section{Funding resources}

No external fund was received. 


\section{REFERENCES}

1. Ahmad M, Khan MA, Marwat SK. Useful medicinal flora enlisted in Holy Quran and Ahadith. Am Eurasian J Agric Environ Sci. 2009;5(1):126-140.

2. Purbafrani A, Hashemi G, Bayyenat SA, Moghaddam S, Saeidi HT, M. The benefits of honey in Holy Quran. Int J Pediatr. 2014;2(3):67-73.

3. Tosun M. Detection of adulteration in honey samples added various sugar syrups with 13C/12C isotope ratio analysis method. Food Chem. 2013;138(2-3):1629-1632. Available from: 10.1016/j.foodchem.2012.11.068.

4. James OO, Mesubi MA, Usman LA, Yeye SO, Ajanaku KO, Ogunniran KO, et al. Physical characterisation of some honey samples from North-Central Nigeria. Int J Phys Sci. 2009;4(9):464-470.

5. Chandrasekaran M, Bahkali AH. Valorization of date palm (Phoenix dactylifera) fruit processing by-products and wastes using bioprocess technology - Review. Saudi J Biol Sci. 2013;20(2):105-120. Available from: 10.1016/j.sjbs.2012.12.004.

6. Hasnaoui A, Elhoumaizi A, Hakkou A, Wathelet B, Sindic M. Physico-chemical characterization, classification and quality evaluation of date palm fruits of some Moroccan cultivars. J Sci Res. 2011;3(1):139-149. Available from: 10.3329/jsr.v3i1.6062.

7. Assirey EAR. Nutritional composition of fruit of 10 date palm (Phoenix dactylifera L.) cultivars grown in Saudi Arabia. J Taibah Univ Sci. 2015;9(1):75-79. Available from: 10.1016/j.jtusci.2014.07.002.

8. Atkinson FS, Brand-Miller JC, Foster-Powell K, Buyken AE, Goletzke J. International tables of glycemic index and glycemic load values 2021: a systematic review. Am J Clin Nutr. 2021;114(5):1625-1632. Available from: 10.1093/ajcn/nqab233.

9. Mckeown NM, Meigs JB, Liu S, Saltzman E, Wilson PW, Jacques PF. Carbohydrate nutrition, insulin resistance, and the prevalence of the metabolic syndrome in the Framingham Offspring Cohort. Diabetes Care. 2004;27(2):538-546. Available from: 10.2337/diacare.27.2.538.

10. Van Dam RM, Visscher AW, Feskens EJ, Verhoef P, Kromhout D. Dietary glycemic index in relation to metabolic risk factors and incidence of coronary heart disease: the Zutphen Elderly Study. Eur J Clin Nutr. 2000;54(9):726-731. Available from: 10.1038/sj.ejcn.1601086.

11. Venn BJ, Green TJ. Glycemic index and glycemic load: measurement issues and their effect on diet-disease relationships. Eur J Clin Nutr. 2007;61(1):122-131. Available from: 10.1038/sj.ejcn.1602942.

12. Atkinson FS, Foster-Powell K, Brand-Miller JC. International tables of glycemic index and glycemic load values. Diabetes Care. 2008;31(12):2281-2283. Available from: $10.2337 / \mathrm{dc} 08-1239$.

13. Aston LM, Gambell JM, Lee DM, Bryant SP, Jebb SA. Determination of the glycaemic index of various staple carbohydrate-rich foods in the UK diet. Eur J Clin Nutr. 2008;62(2):279-285. Available from: 10.1038/sj.ejcn.1602723.

14. E P. The glycemic index: applications in practice. CRC Press; 2016. . 
15. Foster-Powell K, Holt SH, Brand-Miller JC. International table of glycemic index and glycemic load values: 2002. Am J Clin Nutr. 2002;76(1):5-56. Available from: 10.1093/ajcn/76.1.5.

16. Ferruzzi MG, Jonnalagadda SS, Liu S. Developing a standard definition of wholegrain foods for dietary recommendations: summary report of a multidisciplinary expert roundtable discussion. Adv Nutr. 2014;5(2):164-176. Available from: 10. 3945/an.113.005223.

17. Goff HD, Repin N, Khoury DE, Gidley MJ. Dietary fibre for glycaemia control: Towards a mechanistic understanding. Bioact Carbohydr Diet Fibre. 2018;14:3953. Available from: 10.1016/j.bcdf.2017.07.005.

18. WHO/FAO Expert Consultation. Diet, nutrition and the prevention of chronic diseases; 2003.

19. Ferrannini E, Gastaldelli A, Miyazaki Y, Matsuda M, Mari A, Defronzo RA. Betacell function in subjects spanning the range from normal glucose tolerance to overt diabetes: a new analysis. J Clin Endocrinol Metab. 2005;90(1):493-500. Available from: 10.1210/jc.2004-1133.

20. Tappy L, Lê KA. Metabolic effects of fructose and the worldwide increase in obesity. Physiol Rev. 2010;90(1):23-46. Available from: 10.1152/physrev.00019.2009.

21. Mai BH, Yan LJ. The negative and detrimental effects of high fructose on the liver, with special reference to metabolic disorders. Diabetes Metab Syndr Obes. 2019;12:821-826. Available from: 10.2147/DMSO.S198968.

22. Bhupathiraju SN, Tobias DK, Malik VS. Glycemic index, glycemic load, and risk of type 2 diabetes: results from 3 large US cohorts and an updated meta-analysis. Am J Clin Nutr. 2014;100(1):218-232. Available from: 10.3945/ajcn.113.079533.

23. Nantel G, FAO/WHO. Carbohydrates in human nutrition; 1998.

24. Shanahan JF, Davis KJ, editors. Harrison's principles of internal medicine. McGrawHill Education; 2015.

25. Al-Nuzal SMD, Faraj BH. Impact of wheat bran addition to Iraqi bread on postprandial glycaemia. Eng Technol J. 2018;36(C-2):159-164. Available from: 10.30684/etj. 36.2C.11.

26. Rajab AMA, Takruri HRH, Mishal AA, Alkurd RA. Glycemic and insulinemic response of different types of Jordanian honey in healthy and type 2 diabetic volunteers. Pakistan J Nut. 2017;16(2):61-68. Available from: 10.3923/pjn.2017.61.68.

27. Dereje N, Bekele G, Nigatu Y, Worku Y, Holland RP. Glycemic index and load of selected Ethiopian foods: An experimental study. J Diabetes Res. 2019;p. 8564879. Available from: 10.1155/2019/8564879.

28. American Diabetes Association. Diagnosis and classification of diabetes mellitus. Diabetes Care. 2010;33(4):62-69. Available from: 10.2337/dc10-S062.

29. Robert SD, Ismail AA. Two varieties of honey that are available in Malaysia gave intermediate glycemic index values when tested among healthy individuals. Biomed Pap Med Fac Univ Palacky Olomouc Czech Repub. 2009;153(2):145-147. Available from: 10.5507/bp.2009.024. 
30. Algeffari MA, Almogbel ES, Alhomaidan HT, El-Mergawi R, Barrimah IA. Glycemic indices, glycemic load and glycemic response for seventeen varieties of dates grown in Saudi Arabia. Ann Saudi Med. 2016;36(6):397-403. Available from: 10.5144/ 0256-4947.2016.397.

31. Zhang CR, Aldosari S, Shukla P, Nair M, Arabia S. Determination of the variability of sugars in date fruit varieties. J Plant Crops. 2015;43(1):53-61.

32. Arcot J, Brand-Miller J, Rural Industries Research and Development Corporation. A preliminary assessment of the glycemic index of honey. 2005;

33. Alkaabi JM, Al-Dabbagh B, Saadi AS, Gariballa HF, Ghazali S, A M. Glycemic indices of five varieties of dates in healthy and diabetic subjects. Nutr J. 2011;10. Available from: 10.1186/1475-2891-10-59.

34. Effect of storage and processing temperatures on honey quality. J Babylon Univ Pure Appl Sci. 2013;21(6):2244-2253.

35. Basciano H, Federico L, Adeli K. Fructose, insulin resistance, and metabolic dyslipidemia. Nutr Metab (Lond). 2005;2(1). Available from: 10.1186/1743-7075-2-5.

36. Jadoon KA, Ratcliffe SH, Barrett DA. Efficacy and safety of cannabidiol and tetrahydrocannabivarin on glycemic and lipid parameters in patients with type 2 diabetes: A randomized, double-blind, placebo-controlled, parallel group pilot study. Diabetes Care. 2016;39(10):1777-1786. Available from: 10.2337/dc16-0650.

37. Malik VS, Hu FB. Sweeteners and risk of obesity and type 2 diabetes: The role of sugar-sweetened beverages. Curr Diab Rep. 2012;Available from: 10.1007/s11892012-0259-6.

38. Brand-Miller J, Hayne S, Petocz P, Colagiuri S. Low-glycemic index diets in the management of diabetes: a meta-analysis of randomized controlled trials. Diabetes Care. 2003;26(8):2261-2267. Available from: 10.2337/diacare.26.8.2261.

39. Kung B, Turgeon SL, Vien S. Role of amino acids in blood glucose changes in young adults consuming cereal with milks varying in casein and whey concentrations and their ratio. J Nutr. 2020;150(12):3103-3113. Available from: 10.1093/jn/nxaa275.

40. Khan SH, Masood U, Hanif MS, Bokhari SORS, Khan MJ. Effect of age and gender on blood lipids and glucose. Rawal Med J. 2012;37(4).

\section{AUTHOR BIOGRAPHY}

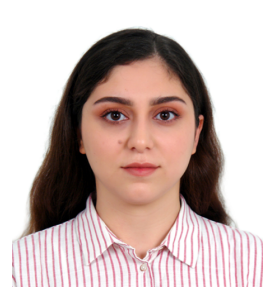

Dalia A. Ali Assistant lecturer (M.Sc.) of biochemistry at the Department of Food Science and Quality Control, College of Agricultural Engineering Sciences, University of Sulaimani (Sulaymaniyah, Iraq). 


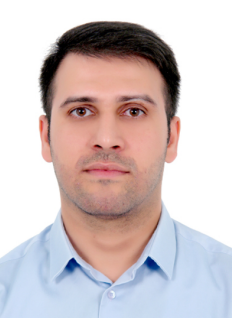

Reder R. Mohammedsalih Assistant lecturer (M.Sc.) of nutrition and food science at the Department of Food Science and Quality Control, College of Agricultural Engineering Sciences, University of Sulaimani (Sulaymaniyah, Iraq). He is a member of British Association for Parenteral and Enteral Nutrition (BAPEN), American Society of Nutrition (ASN), and the Canadian Nutrition Society (CNS).

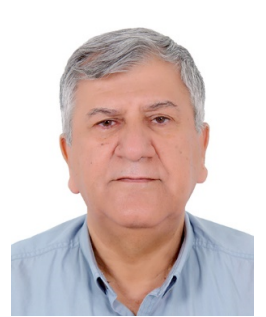

Rafiq M.S. Rashid Assistant professor (Ph.D.) of human nutrition at the Department of Food Science and Quality Control, College of Agricultural Engineering Sciences, University of Sulaimani (Sulaymaniyah, Iraq). 